\title{
Forest Cover Index for Tree Cover Detection Using Landsat-7 Multispectral Imagery
}

Luisa I. Feliciano-Cruz, Sarah J. Becker, Kristofer D. Lasko,

Craig S.T. Daughtry, and Andrew L. Russ

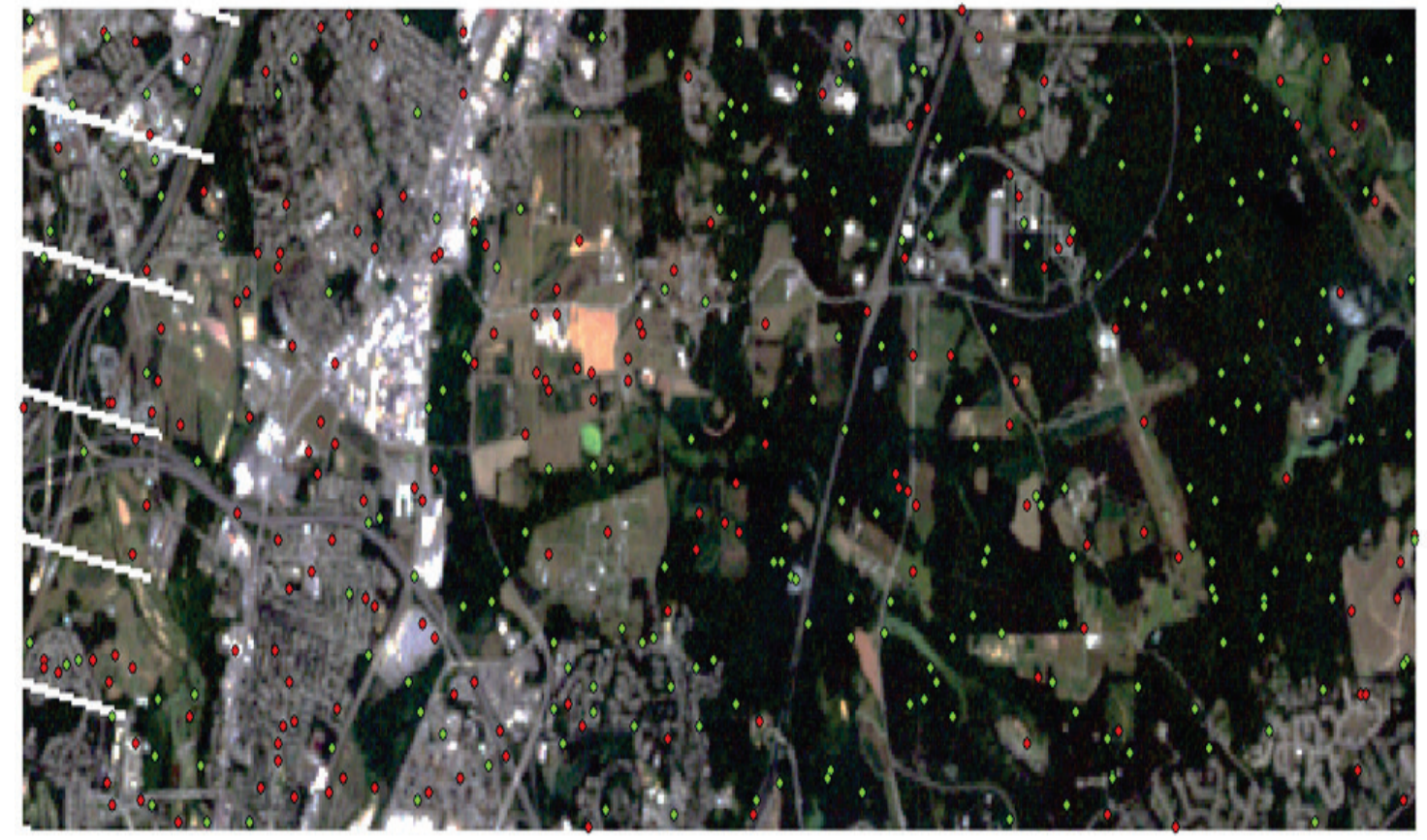


The U.S. Army Engineer Research and Development Center (ERDC) solves the nation's toughest engineering and environmental challenges. ERDC develops innovative solutions in civil and military engineering, geospatial sciences, water resources, and environmental sciences for the Army, the Department of Defense, civilian agencies, and our nation's public good. Find out more at www.erdc.usace.army.mil.

To search for other technical reports published by ERDC, visit the ERDC online library at http://acwc.sdp.sirsi.net/client/default. 


\title{
Forest Cover Index for Tree Cover Detection Using Landsat-7 Multispectral Imagery
}

\author{
Luisa I. Feliciano-Cruz, Sarah J. Becker, and Kristofer D. Lasko \\ U.S. Army Engineer Research and Development Center (ERDC) \\ Geospatial Research Laboratory (GRL) \\ 7701 Telegraph Road. \\ Alexandria, VA 22315 \\ Craig S.T. Daughtry, and Andrew L. Russ \\ Hydrology and Remote Sensing Laboratory \\ U.S. Department of Agriculture (USDA) Agricultural Research Service \\ 5601 Sunnyside Avenue \\ Beltsville, MD 20705
}

Final Report

Approved for public release; distribution is unlimited.

Prepared for Headquarters, U.S. Army Corps of Engineers

Washington, DC 20314-1000

Under Geospatial Analysis at the Tactical Edge (GATE): 405906 and 405908, Geoenabled Augmented Intelligence for Decisive Engagement (GAIDEN): 0602784A-855-24, and Geo-Intelligence in Complex Urban Environments (GeolCUE): 62784 


\section{Abstract}

Forest cover monitoring using satellite imagery is important to U.S. military terrain analysis. Mobility models, cover and concealment, and precise surface feature delineation all rely on an accurate forest/nonforest cover layer. However, the challenge remains in distinguishing trees from other vegetative land covers when relying on single date imagery. A Forest Cover Index (FCI) algorithm was previously developed on Worldview-2 imagery and was designed to separate forest cover from nonforest covered areas. In this research, the FCI algorithm was applied to Landsat-7 imagery using the analogous red (636-673 nanometers (nm)) and near-infrared bands $(851-878 \mathrm{~nm})$ from a peak summer image on 16 August 2012. The results obtained with Landsat-7 imagery proved satisfactory with an overall accuracy (tree cover versus non-tree cover) of $>83$ percent, according to testing with two different accuracy assessment tests. The application of the FCI to Landsat-7 imagery broadens the applicability of the FCI to freely available imagery.

DISCLAIMER: The contents of this report are not to be used for advertising, publication, or promotional purposes. Citation of trade names does not constitute an official endorsement or approval of the use of such commercial products. All product names and trademarks cited are the property of their respective owners. The findings of this report are not to be construed as an official Department of the Army position unless so designated by other authorized documents. 


\section{Contents}

Abstract.............................................................................................................................................. ii

Figures and Tables .................................................................................................................... iv

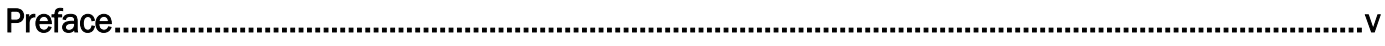

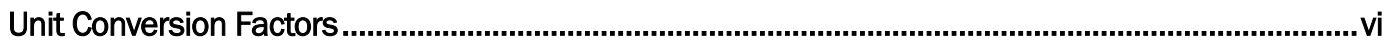

Acronyms and Abbreviations ..................................................................................................... vii

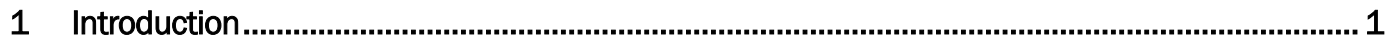

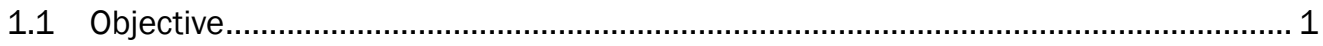

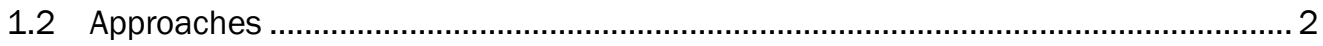

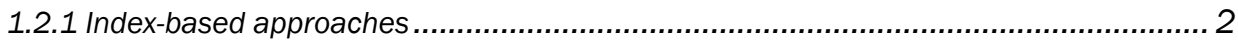

1.2.2 Classification-based approaches ..................................................................... 2

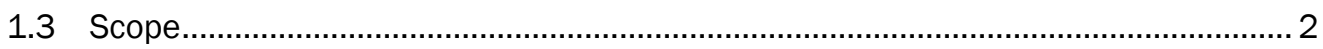

2 Project Background and Description .............................................................................. 3

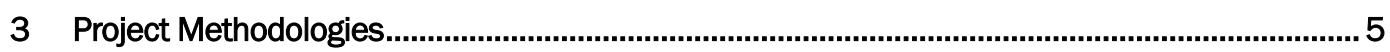

3.1 Landsat-7 FCl workflow and accuracy assessment from purposive sampling

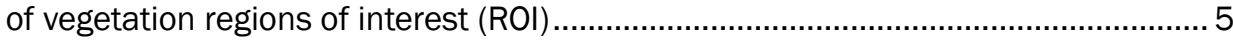

3.2 Stratified-random points accuracy assessment .............................................. 7

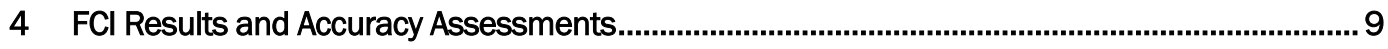

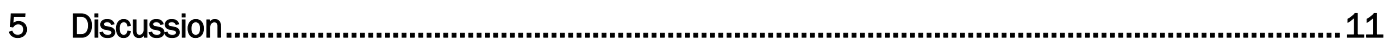

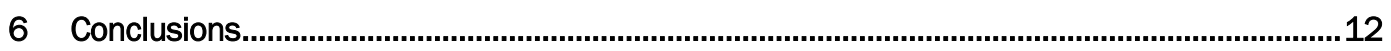

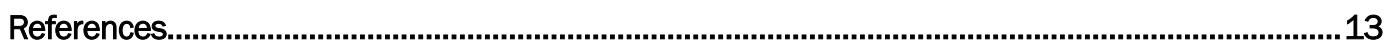

Appendix A: Confusion Matrix for Landsat-7, 16 August 2012, Calculated With ENVI

Classic.

\section{Report Documentation Page}




\section{Figures and Tables}

\section{Figures}

Figure 1. Landsat-7 image of the Beltsville Agricultural Research Center (BARC) in Beltsville, MD, outlined in red from 16 August 2012.

Figure 2. Landsat-7 image of the BARC from 16 August 2012 showing the Tree (green) and Not Tree (red) ROls.

Figure 3. Schematic of the ModelBuilder workflow for stratified-random point accuracy assessment. 8

Figure 4. This figure shows the result of the $\mathrm{FCl}_{2}$. Forest cover was masked out of the image and other land covers remained visible. 9

Figure 5. Stratified-random points for accuracy assessment. Red represents Not Tree, while the green represents Tree ground truth points. 10

\section{Tables}

Table 1. Landsat-7 results for user's, producer's, and overall accuracy, as well as the Kappa statistic for $\mathrm{FCl}_{2}$ using purposive sampling.

Table 2. Landsat-7 results for user's, producer's, and overall accuracy, as well as the Kappa statistic for $\mathrm{FCl}_{2}$, employing stratified-random accuracy assessment points. 


\section{Preface}

This work was performed by the Geospatial Analysis at the Tactical Edge, Geo-enabled Augmented Intelligence for Decisive Engagement, and GeoIntelligence in Complex Urban Environments work packages under projects Geospatial Analysis at the Tactical Edge (GATE), 405906 and 405908, Geo-enabled Augmented Intelligence for Decisive Engagement (GAIDEN), 0602784A-855-24, and Geo-Intelligence in Complex Urban Environments (GeoICUE), 62784.

The work was performed by the U.S. Army Engineer Research and Development Center, Geospatial Research Laboratory (ERDC-GRL). At the time of publication, Ms. Jennifer Smith was the chief, CEERD-TRS, Ms. Martha Kiene was the chief, CEERD-TR, Dr. Robert L. Fischer, CEERD-TR was the Technical Director for ERDC-GRL. The Deputy Director of ERDC-GRL was Ms. Valerie L. Carney and the Director was Mr. Gary W. Blohm.

COL Teresa A. Schlosser was Commander of ERDC, and Dr. David W. Pittman was the Director. 


\section{Unit Conversion Factors}

\begin{tabular}{|l|l|l|}
\hline Multiply & By & To Obtain \\
\hline acres & $4,046.873$ & square meters \\
\hline acre-feet & $1,233.5$ & cubic meters \\
\hline cubic feet & 0.02831685 & cubic meters \\
\hline cubic inches & $1.6387064 \mathrm{E}-05$ & cubic meters \\
\hline cubic yards & 0.7645549 & cubic meters \\
\hline degrees (angle) & 0.01745329 & radians \\
\hline feet & 0.3048 & meters \\
\hline hectares & $1.0 \mathrm{E}+04$ & square meters \\
\hline inches & 0.0254 & meters \\
\hline miles (nautical) & 1,852 & meters \\
\hline miles (U.S. statute) & $1,609.347$ & meters \\
\hline slugs & 14.59390 & kilograms \\
\hline square feet & 0.09290304 & square meters \\
\hline square inches & $6.4516 \mathrm{E}-04$ & square meters \\
\hline square miles & $2.589998 \mathrm{E}+06$ & square meters \\
\hline square yards & 0.8361274 & square meters \\
\hline yards & 0.9144 & meters \\
\hline & & \\
\hline
\end{tabular}




\section{Acronyms and Abbreviations}

\begin{tabular}{|l|l|}
\hline BARC & Beltsville Agricultural Research Center \\
\hline DoD & Department of Defense \\
\hline ENVI & Environment for Visualizing Images \\
\hline ESRI & Environmental Systems Research Institute \\
\hline FCI & Forest Cover Index \\
\hline GRL & Geospatial Research Laboratory \\
\hline $\mathrm{m}$ & meter \\
\hline NDVI & Normalized Difference Vegetation Index \\
\hline nm & nanometers \\
\hline ROI & Regions Of Interest \\
\hline USACE & U.S. Army Corps of Engineers \\
\hline USDA & U.S. Department of Agriculture \\
\hline
\end{tabular}




\section{Introduction}

The mapping of forest cover in heterogeous land-use images is challenging because forest cover can be indistinguishable from other types of vegetation in multispectral imagery (Becker et al. 2018). Healthy forest cover demonstrates a similar spectral profile to other healthy green vegetation with variations based on vigor, water content, and cell structure (Becker et al. 2018; Knipling 1970). Prior research has explored techniques to map forest cover using index and classification-based approaches, as described in section 1.2, but has fallen short in consistently detecting tree cover in complex environments.

\subsection{Objective}

The objective of this project is to apply the Forest Cover Index (FCI) algorithm, FCI2, to Landsat-7 multispectral imagery. This will provide scientists and researchers, who do not have access to DigitalGlobe WorldView multispectral satellite imagery, the opportunity to employ the FCI for forest cover detection using freely-available multispectral imagery.

The specific project objectives are the following:

- Test the FCI workflow for forest canopy detection using freely available Landsat-7 multispectral imagery in both ArcGIS (Environmental Systems Research Institute (ESRI), Redlands, California) and Environment for Visualizing Images (ENVI) software (Harris Corporation, Melbourne, Florida). The imagery will be from the U.S. Department of Agriculture (USDA) Henry A. Wallace Beltsville Agricultural Research Center (BARC) near Beltsville, $\mathrm{MD}\left(39.025^{\circ} \mathrm{N}\right.$, $\left.76.850^{\circ} \mathrm{W}\right)$.

- Perform an accuracy assessment of the results using a non-random sampling technique comparing results to known vegetative land cover polygons to generate a performance (confusion) matrix including user's, producer's, and overall accuracy, and the Kappa statistic (Appendix A).

- Conduct a more robust accuracy assessment using a stratified-random sampling technique with unbiased areal proportions, and compare with the non-random technique. 
- Automate the workflow for the forest cover indices using ArcGIS ModelBuilder.

\subsection{Approaches}

\subsubsection{Index-based approaches}

The Normalized Difference Vegetation Index (NDVI), as well as similar vegetation indices have been developed as indicators of vegetation greenness or health in remotely-sensed imagery (Rouse et al. 1974) and have been used to delineate vegetative from non-vegetative land covers (Jackson and Huete 1991; Kaplan and Avdan 2017). Even though these indices monitor forest states and canopy processes (Jinguo and Wei 2004; Huete 2012), none has been found to consistently aid in distinguishing between forest cover and other vegetative land cover classes. For example, Bunting and Lucas (2006) focused on tree cover and applied red edge and red band ratios, and selected the maximum value in imagery and achieved accuracies ranging from 19.2 to 91.6 percent in delineating tree crowns depending on the stem diameter at breast height.

\subsubsection{Classification-based approaches}

Other researchers have employed supervised and unsupervised classification techniques to identify forest cover in imagery with varying degrees of success, with forest cover often confused with agriculture or rangeland (Yuan et al. 2005; Ye et al. 2014; Akar et al. 2017). For a comprehensive literature review on prior research in mapping forest cover in multispectral imagery, please see Becker et al. (2018).

\subsection{Scope}

Becker et al. (2018) addressed the need to detect forest cover in imagery by developing two FCI algorithms that reliably distinguish trees from other types of vegetation in two meter (m) spatial resolution WorldView-2 multispectral imagery at the BARC. This research expands on the results reported by Becker et al. (2018) applying the FCI to 30-m Landsat-7 multispectral imagery to distinguish forest cover from other vegetated land cover classes. 


\section{Project Background and Description}

This research developed a methodology for distinguishing forest cover from other land cover types using moderate resolution multispectral imagery. Since traditional vegetation indices and classification techniques do not consistently separate out tree from other land covers, as described in section 1, two forest cover indices, $\mathrm{FCI}_{1}$ and $\mathrm{FCI}_{2}$, were developed by Becker et al. (2018) to separate forest from other land covers. Becker et al. (2018) found that by multiplying reflectance in the red and red edge, as well as in the red and near-infrared bands, a delineation between trees and other vegetative land covers was observed. The FCIs are shown in the following equations:

$$
\begin{aligned}
& \mathrm{FCl}_{1}=\mathrm{R}_{660} * \mathrm{R}_{725} \\
& \mathrm{FCl}_{2}=\mathrm{R}_{660} * \mathrm{R}_{835}
\end{aligned}
$$

Where, $\mathrm{R}_{660}, \mathrm{R}_{725}$, and $\mathrm{R}_{835}$ represent reflectance in red, red edge, and near-infrared bands, respectively (Becker et al. 2018).

Becker et al. (2018) conducted the initial test at the BARC (Figure 1). The site is comprised of 2,500 hectares of intermixed agricultural fields, pastures, conifer and deciduous woodlands, wetlands, and some urban areas. Typical soil has a sandy-textured surface layer and a taxonomic classification of coarse-loamy, siliceous, mesic Typic Hapludults (Soil Survey Staff 2018). The study site is located in the coastal plain and consists of fairly flat to gently sloping uplands. The climate is humid subtropical with precipitation occurring throughout the year (Weatherbase 2018). 
Figure 1. Landsat-7 image of the Beltsville Agricultural Research Center (BARC) in Beltsville, MD, outlined in red from 16 August 2012.

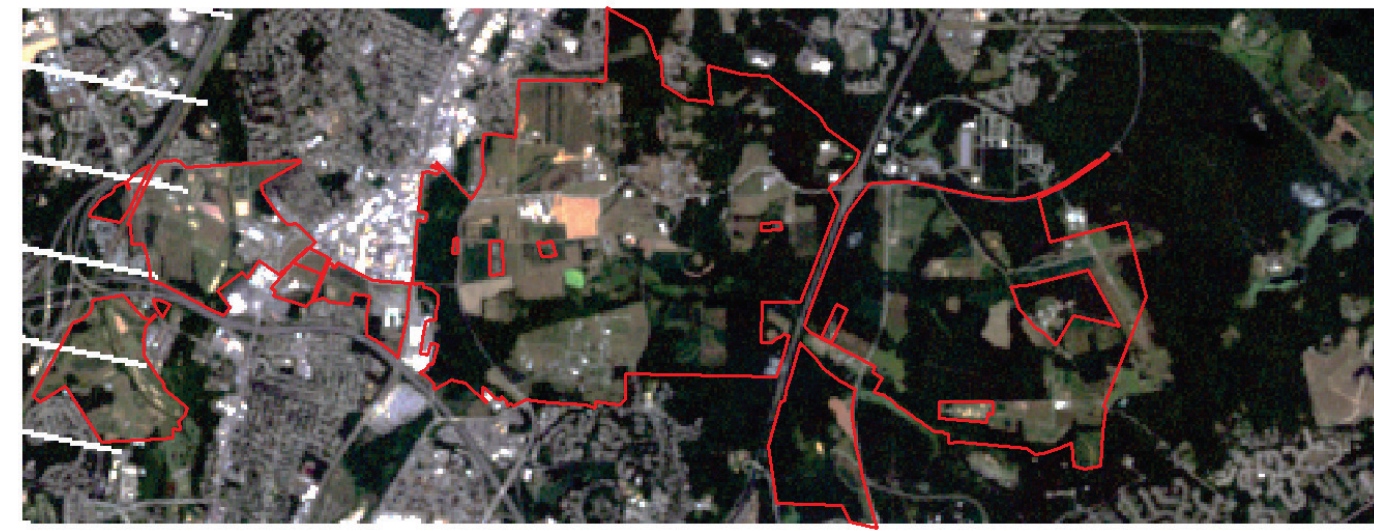

Becker et al. (2018) developed the FCI's using WorldView-2 multispectral imagery. The seasonality of the tree cover was measured by selecting one date for each season: 27 May 2012, 05 Aug 2012, 26 Oct 2014, and 18 Jan 2013. Once the forest cover indices were applied to the imagery, a threshold for separating Tree vs. Not Tree was manually obtained through trial and error. This threshold was then used to produce a masked image.

Our research expands upon the research by Becker et al. (2018) by testing the workflow used for the initial study with freely-available Landsat-7 multispectral imagery. Landsat-7 contains reflectance bands in the visible through thermal infrared regions of the electromagnetic spectrum but does not include a red edge band, the workflow will only test the applicability of $\mathrm{FCI}_{2}$ on Landsat-7 imagery. 


\section{Project Methodologies}

According to the specific objectives of the research defined in section 1, the project methodologies are cataloged as 1) Landsat-7 FCI test and accuracy assessment using ground truth based on vegetation types obtained in the field, and 2) an accuracy assessment using stratified-random points and high resolution satellite imagery (i.e., Worldview-2).

\subsection{Landsat-7 FCl workflow and accuracy assessment from purposive sampling of vegetation regions of interest (ROI)}

This research tested the workflow outlined in Becker et al. (2018) on Landsat-7 red and near infrared bands acquired on 16 August 2012. The FCI2 equation as applied to Landsat-7 is as follows:

$$
\mathrm{FCl}_{2}=\mathrm{R}_{655} * \mathrm{R}_{865}
$$

Where, $\mathrm{R}_{655}$ and $\mathrm{R}_{865}$ represent reflectance in red and near infrared bands, respectively. While this research was tested using ENVI Classic software, the user can perform the following steps in a preferred remote sensing software package:

1. Apply the $\mathrm{FCI}_{2}$ algorithm to the Landsat-7 image to generate the $\mathrm{FCI}_{2}$ image.

2. Examine different land covers in the $\mathrm{FCI}_{2}$ grayscale image to determine a user-defined threshold value that separates trees from other vegetation covers.

3. Build a mask to separate trees below the threshold value.

4. Apply the mask to the original image, resulting in an image that masks all of the tree pixels.

The accuracy assessment applied to this research measures the agreement between a classified image generated through remote sensing analysis against reference data (i.e., ground-truth data or high-resolution imagery) that is anticipated to be correct. For this research, 2-m WorldView-2 imagery was used as reference data. This is usually performed through a confusion matrix, yielding an overall accuracy and the Kappa statistic. According to Congalton and Mead (1986), confusion matrices also describe the errors of inclusion (commission errors as measured in the user's accuracy) and errors of exclusion (omission errors as measured in 
the producer's accuracy) present in a classified image. A commission error occurs when a pixel is incorrectly included in the class to which it does not belong, and an omission error occurs when a pixel is excluded from the class to which it belongs (Congalton and Green 2009). In summary, every error on the classified image is an omission from the correct class or a commission to an incorrect class. This analysis aids in obtaining an overall accuracy, which in the confusion matrix is the sum of the major diagonal (i.e., the number of correctly classified pixels) divided by the total number of pixels in the image.

To generate a confusion matrix, the user identifies regions of interest (ROI) from ground truth data and compares the ROIs to the classified data. For this research, two classes were created, "Tree" and "Not Tree," containing 66 ROI polygons (Figure 2). The Tree category included ten conifer and ten deciduous ROIs. The "Not Tree" category included thirty ROIs of annual crops (alfalfa, barley, corn, orchardgrass, rye, ryegrass, soybean, turf grass, triticale, and wheat), ten perennial grass pastures, and six golf courses. The ROIs were identified using a non-random purposive sampling technique, where the researcher had prior knowledge of the ROIs and selected them to represent the diverse array of vegetative land cover classes throughout the image. Using a non-random sampling technique, such as the purposive sampling technique, is less robust and introduces bias, which makes results appear better than they actually are. The technique was selected to ensure a variety of vegetative land cover classes were included and compared to forest cover. Including this technique also gives the ability to compare accuracy with the stratified random sampling technique, as discussed in the section below.

Kappa is a statistic that measures agreement between the classified and ground truth images (Cohen 1960; McHugh 2012; Congalton et al. 1983). Landis and Koch (1977) assigned ranges for Kappa to categorize agreement. According to Landis and Koch (1977), Kappa values greater than 80\% represent strong agreement, values between $40-80 \%$ represent moderate to substantial agreement, and values below $40 \%$ represent poor agreement. 
Figure 2. Landsat-7 image of the BARC from 16 August 2012 showing the Tree (green) and Not Tree (red) ROls.

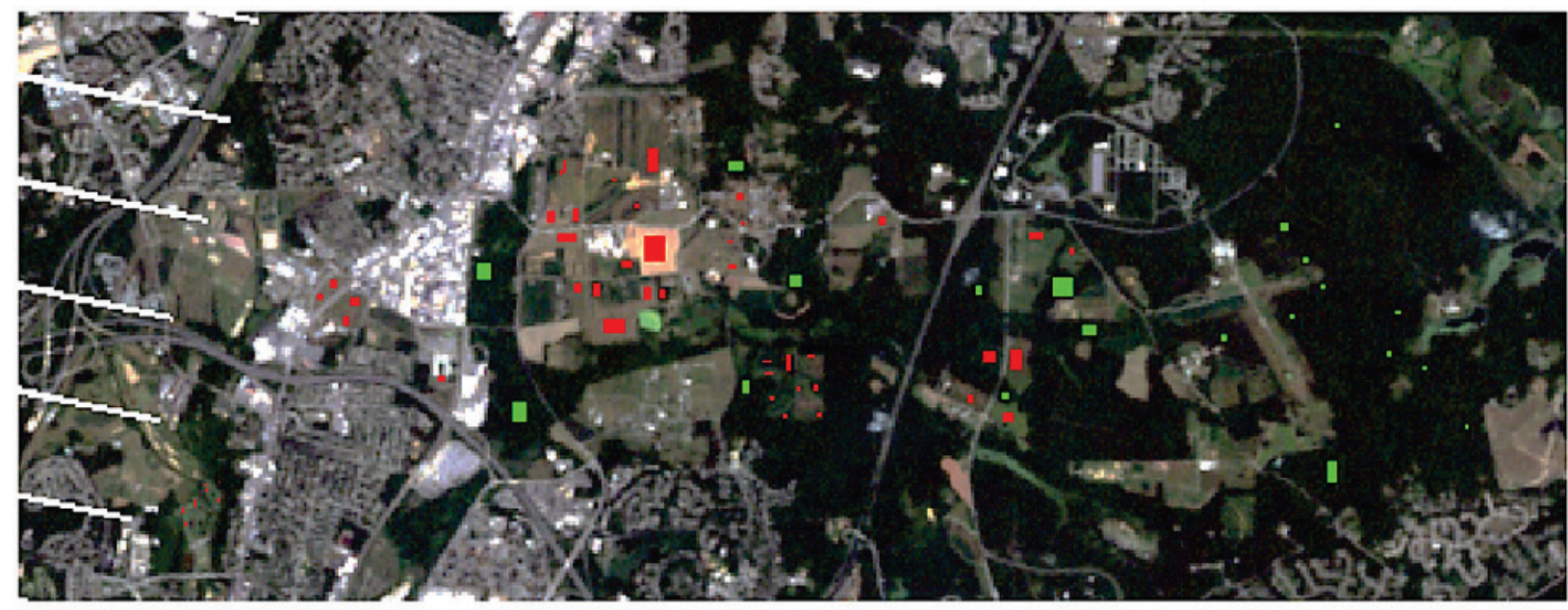

\subsection{Stratified-random points accuracy assessment}

The second accuracy assessment was conducted using land covers based on a stratified-random sample of points for all land cover types in the Landsat-7 image with WorldView-2 as reference data. Multinomial probability sampling was used to calculate how many points are needed. The number of sample points, $N$, is determined by:

$$
N=\frac{B \Pi_{i}\left(1-\Pi_{i}\right)}{b_{i}^{2}}
$$

Where, $\Pi_{i}$ represents the proportion of a population in the $i^{\text {th }}$ class out of $k$ number of classes, $b$ is the precision, and $B$ is the upper $(\alpha / \mathrm{k})^{*} 100$ th percentile of the chi-square $\left(X^{2}\right)$ distribution with one degree of freedom (Congalton and Green 2009). The number of sample points are divided amongst the different classes in proportion to their area.

To generate the confusion matrix, the initial ROIs are replaced by a set of random points for classification and ground truth data. The workflow involves the following three ArcGIS geoprocessing tools: Create Accuracy Assessment Points, Update Accuracy Assessment Points, and Compute Confusion Matrix (ESRI 2018). A semi-automated workflow was constructed in ArcGIS ModelBuilder for computing the $\mathrm{FCI}_{2}$ and the confusion matrix in the stratified-random point accuracy assessment (Figure 3). 
ERDC/GRL TR-19-1

8

Figure 3. Schematic of the ModelBuilder workflow for stratified-random point accuracy assessment.

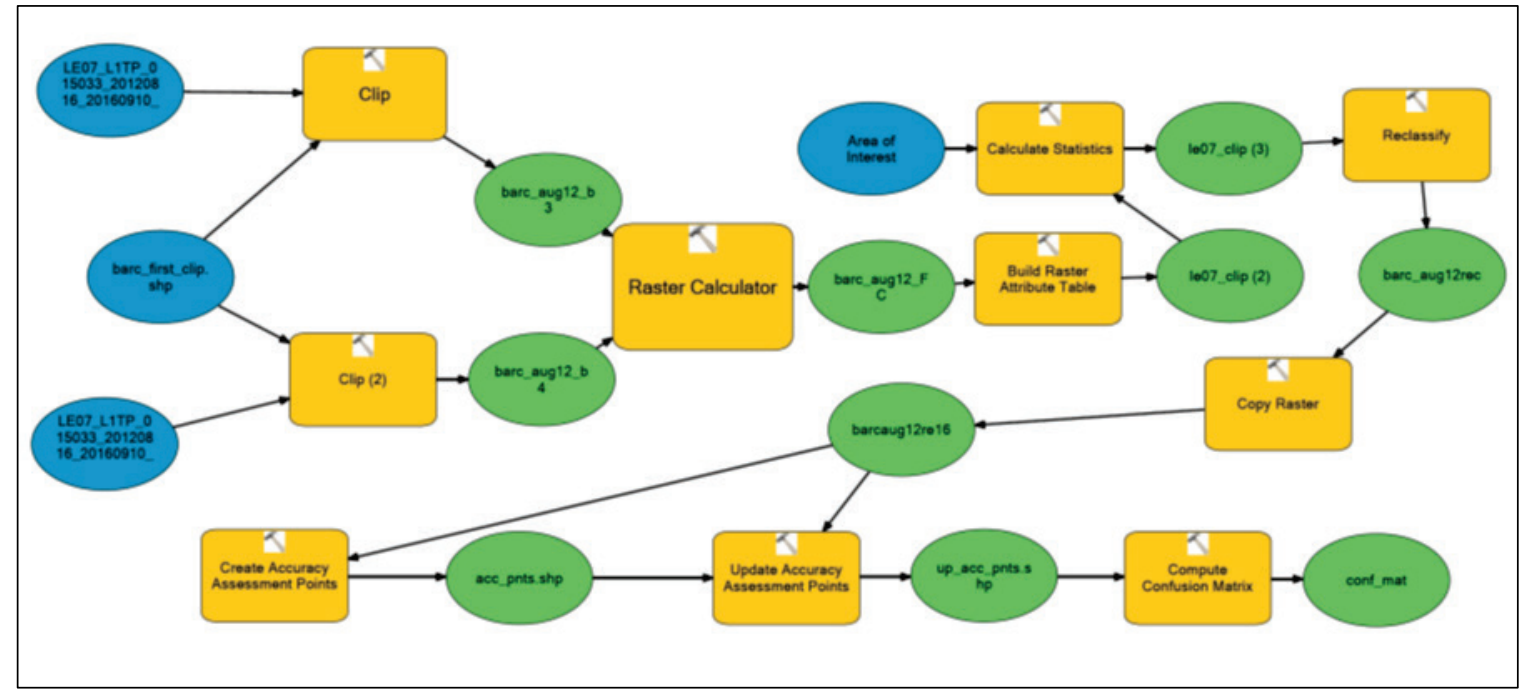




\section{FCI Results and Accuracy Assessments}

The workflow to apply the $\mathrm{FCI}_{2}$ to Landsat-7 imagery yielded raster output where the trees were masked out of imagery and other land covers remained visible (Figure 4). The resulting confusion matrices (purposive sampling and random sampling) for the classifications are included in Appendix A. Table 1 and Table 2 summarize the accuracy assessment for the 66 ROIs. Depending on the accuracy assessment type, the overall accuracy ranged from $83.7 \%$ to $95.5 \%$ with Kappa of $67.5 \%$ and $90.6 \%$ representing agreement between classification and ground truth data. Dark vegetation, such as dense agriculture, was misclassified as forest cover in some instances because the $\mathrm{FCI}_{2}$ values for agriculture overlapped with forest values. Even though dense agriculture was present throughout the image, the $\mathrm{FCI}_{2}$ still successfully differentiated between most of it and forest cover. Some non-vegetative dark pixels, such as water bodies, were also misclassified as forest cover in the result, which led to a decrease in accuracy.

Figure 4. This figure shows the result of the $\mathrm{FCl}_{2}$. Forest cover was masked out of the image and other land covers remained visible.

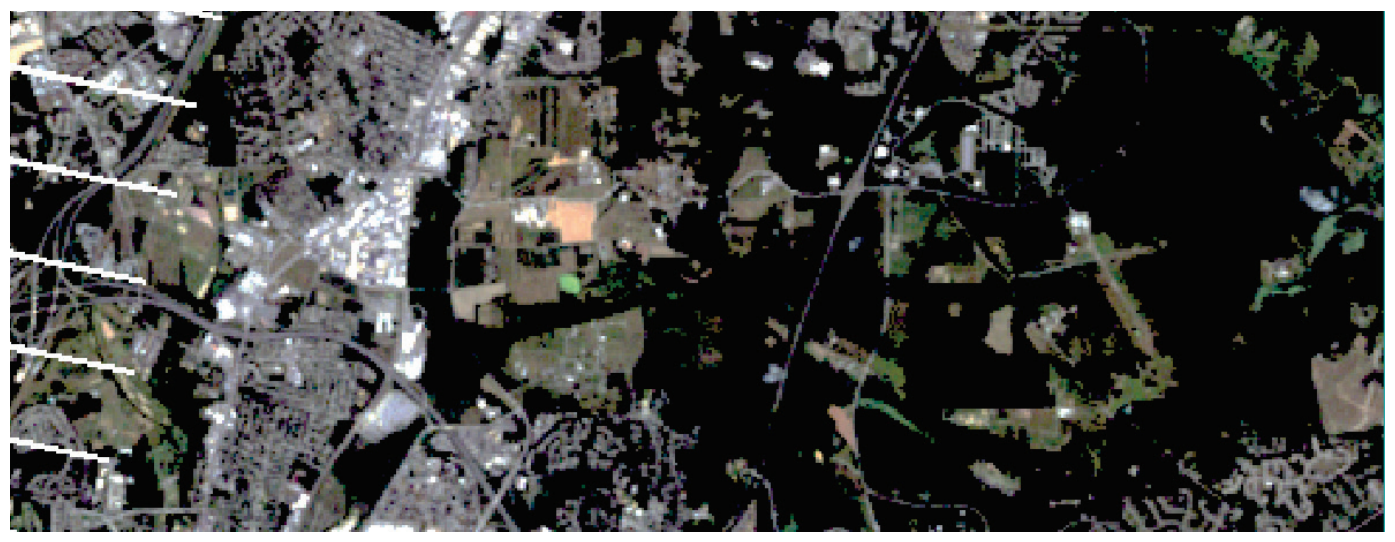

Table 1. Landsat-7 results for user's, producer's, and overall accuracy, as well as the Kappa statistic for $\mathrm{FCl}_{2}$ using purposive sampling.

\begin{tabular}{|c|c|c|c|c|c|c|}
\hline \multirow[b]{2}{*}{ Date } & \multirow[b]{2}{*}{ Class } & \multicolumn{3}{|c|}{ Accuracy (\%) } & \multirow[b]{2}{*}{ Kappa } & \multirow[b]{2}{*}{ Variance } \\
\hline & & Producer & User & Overall & & \\
\hline \multirow{2}{*}{$\begin{array}{l}16 \text { August } \\
2012\end{array}$} & Tree & 99.9 & 89.2 & \multirow{2}{*}{95.5} & \multirow{2}{*}{90.6} & \multirow{2}{*}{0.0026} \\
\hline & Not Tree & 92.8 & 99.9 & & & \\
\hline
\end{tabular}

A total of 422 sample points were generated based on multinomial probability sampling theory and the chi square distribution with parameters of 1 degree of freedom, a precision of $5 \%$ and $k=2$ classes, 
with $95 \%$ confidence intervals. The two classes were points selected from either Tree or Not Tree classified areas, depending on the area proportions in the resulting map. Since the classified image contains 64,247 Tree pixels, and 27,288 Not Tree pixels, the study area represents about 70\% Tree and 30\% Not Tree. Points laying on the study area's scanline errors were removed, ultimately obtaining 419 sample points. Since there is roughly $70 \%$ Tree, then there should be $419^{*} 70 \%=293$ points representing Tree and $419^{*} 30 \%=126$ points representing Not Tree. Figure 5 shows the resulting stratified-random points for the BARC and Table 2 shows the accuracy assessment. Red represents Not Tree, while the green represents Tree ground truth points.

Figure 5. Stratified-random points for accuracy assessment. Red represents Not Tree, while the green represents Tree ground truth points.

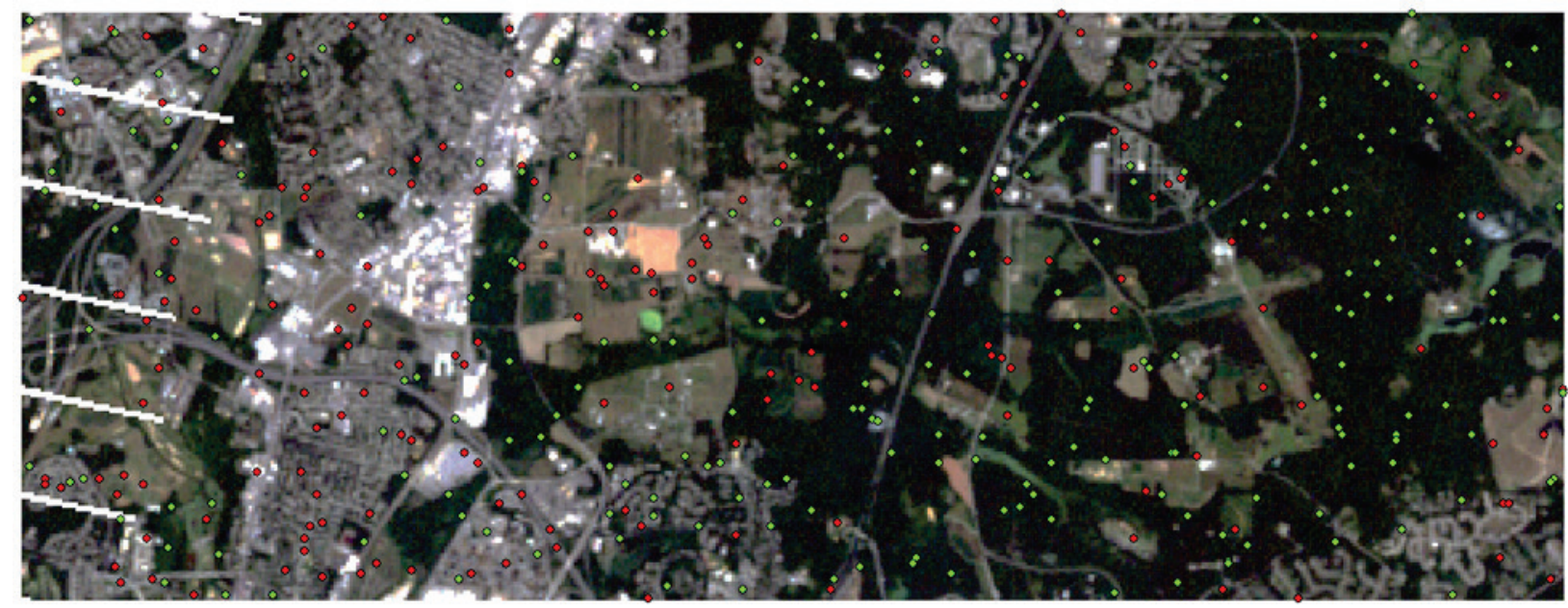

Table 2. Landsat-7 results for user's, producer's, and overall accuracy, as well as the Kappa statistic for $\mathrm{FCl}_{2}$, employing stratified-random accuracy assessment points.

\begin{tabular}{|c|c|c|c|c|c|c|}
\hline \multirow[b]{2}{*}{ Date } & \multirow[b]{2}{*}{ Class } & \multicolumn{3}{|c|}{ Accuracy (\%) } & \multirow[b]{2}{*}{ Kappa } & \multirow[b]{2}{*}{ variance } \\
\hline & & Producer & User & Overall & & \\
\hline \multirow{2}{*}{$\begin{array}{l}16 \text { Aug } \\
2012\end{array}$} & Tree & 77.8 & 91.8 & \multirow{2}{*}{83.7} & \multirow{2}{*}{67.5} & \multirow{2}{*}{0.0027} \\
\hline & Not Tree & 91.1 & 76.3 & & & \\
\hline
\end{tabular}




\section{Discussion}

This study tested an algorithm originally developed for high-resolution WorldView-2 multispectral imagery to differentiate forest from other vegetative land covers using medium-resolution Landsat-7 imagery. The results showed the $\mathrm{FCI}_{2}$ can reliably separate forest from other vegetative land cover classes in a leaf-on Landsat-7 image of Beltsville, MD. The scene included dense forest, agricultural, and urban land cover.

Becker et al. (2018) calculated accuracy statistics using purposive sampling of vegetative ROIs of WorldView-2 imagery and their results were similar to the accuracy using Landsat-7. These results suggest Landsat-7 is a viable alternative when WorldView-2 is not available and when finding individual trees with high resolution imagery is unnecessary.

Prior research has shown that differences in reflectance between the forest canopy and an individual leaf occur because of variations in illumination angle, leaf orientations within the canopy, shadowing, and non-foliage backgrounds present in the image (Knipling 1970). Furthermore, shadowing decreases the spectral response of vegetated pixels (Zhang et al. 2015), which could lead to the lower $\mathrm{FCI}_{2}$ values used to identify forest pixels.

Further testing is suggested to validate the technique in other locations and across changing image dates. This technique was not tested in areas with sparse tree cover or tree species not present in Beltsville, MD. It is also recommended to test the impact of a preliminary image segmentation that separates vegetated from non-vegetated pixels. For example, the NDVI can be used to mask non-vegetative pixels from the image, which could improve the accuracy of the assessment that used stratified-random points because the FCI2 would then only separate tree from other vegetative cover types. Non-vegetative dark pixels, such as water, will no longer be misclassified as forest cover. 


\section{Conclusions}

The use of Landsat-7 imagery yielded good overall accuracy results. FCI2 was successfully applied to freely-available Landsat-7 imagery providing researchers and scientists the ability to employ the FCI without purchasing commercial imagery. A typical WV-2 image with $5 \%$ or less cloud cover is available for $\$ 20$ per 1 square kilometer (or 0.37 square miles), which would be around $\$ 2,000$ for the BARC imagery (Land Info 2018). The results suggest applying the FCI2 to Landsat-7 to detect forest cover could be an alternate to using WorldView-2 to find forest cover when individual trees are not of interest and WorldView-2 is not available.

The overall accuracy for the purposive sampling with ROIs technique was 95.5\% with a Kappa of 90.5. The stratified-random points accuracy assessment with unbiased areal proportions provided improved overall accuracy for FCI2 at $83 \%$ with a Kappa statistic of $67.5 \%$ which is within the acceptable range.

Future research will focus on $\mathrm{FCI}_{2}$ testing across seasons in diverse terrain and within different forest types. Future accuracy assessments will apply the stratified-random points accuracy assessment technique using unbiased areal proportions as it provides an assessment which is proportionally representative of the entire study area. 


\section{References}

Akar, A., E. Gökalp, Ö Akar, and V. Yllmaz. 2017. Improving classification accuracy of spectrally similar land covers in the rangeland and plateau areas with a combination of WorldView-2 and UAV images. Geocarto International 32(9):990-1003. https://doi.org/10.1080/10106049.2016.1178816.

Becker, S. J., C. S. T. Daughtry, and A. L. Russ. 2018. Robust forest cover indices for multispectral images. Photogrammetric Engineering and Remote Sensing 84(8):505-512. https://doi.org/10.14358/PERS.84.8.505.

Bunting, P., and R. Lucas. 2006. The delineation of tree crowns in Australian mixed species forests using Compact Airborne Spectrographic Imager (CASI) data. Remote Sensing of Environment 101(2):230-248. https://doi.org/10.1016/i.rse.2005.12.015.

Cohen, J. 1960. A coefficient of agreement for nominal scales. Educational and Psychological Measurement 20(1):37-40. https://doi.org/10.1177/001316446002000104.

Congalton, R. G., and K. Green. 2009. Assessing the Accuracy of Remotely Sensed Data. Taylor \& Francis, Boca Raton, FL: CRC Press.

Congalton, R. G., and R. A. Mead. 1986. A review of three discrete multivariate analysis techniques used in assessing the accuracy of remotely sensed data from error matrices. IEEE Transactions of Geoscience and Remote Sensing GE-24(1):169174 .

Congalton, R. G., R. G. Oderwald, and R. A. Mead. 1983. Assessing Landsat classification accuracy using discrete multivariate analysis statistical techniques.

Photogrammetric Engineering and Remote Sensing 49(12):1671-1678.

Environmental Systems Research Institute (ESRI). 2018. Accuracy assessment for image classification-Help. (Accessed on 2 November 2018).

http://desktop.arcgis.com/en/arcmap/latest/manage-data/raster-and-images/accuracyassessment-for-image-classification.htm.

Huete, A. R. 2012. Vegetation indices, remote sensing and forest monitoring. Geography Compass 6(9):513-532. https://doi.org/10.1111/j.1749-8198.2012.00507.x.

Jackson, R. D., and A. R. Huete. 1991. Interpreting vegetation indices. Preventive Veterinary Medicine 11(3-4):185-200.

Jinguo, Y., and W. Wei. 2004. Identification of forest vegetation using vegetation indices. Chinese Journal of Population Resources and Environment 2(4):12-16. https://doi.org/10.1080/10042857.2004.10677383.

Kaplan, G., and U. Avdan. 2017. Mapping and monitoring wetlands using SENTINEL-2 satellite imagery. In ISPRS Annals of Photogrammetry, Remote Sensing and Spatial Information Sciences IV-4/W4: 271-277. 
Knipling, E. B. 1970. Physical and physiological basis for the reflectance of visible and near-infrared radiation from vegetation. Remote Sensing of Environment 1(3):155-159. https://doi.org/10.1016/S0034-4257(70)80021-9.

Land Info. 2018. Satellite imagery pricing. Worldwide Mapping LLC. (Accessed on 2 November 2018). https://www.landinfo.com/LAND_INF0_Satellite_Imagery_Pricing.pdf.

Landis, J. R., and G. G. Koch. 1977. The measurement of observer agreement for categorical data. Biometrics 33(1):159-174. https://www.jstor.org/stable/2529310.

McHugh, M. L. 2012. Interrater reliability: The kappa statistic. Biochemia Medica 2(3):276-282. https://hrcak.srce.hr/89395.

Rouse Jr, J. W., R. H. Haas, J. A. Schell, and D. W. Deering. 1974. Monitoring vegetation systems in the Great Plains with ERTS. National Aeronautical and Space Administration (NASA) 351:309-317. https://ntrs.nasa.gov/archive/nasa/casi.ntrs.nasa.gov/19740022614.pdf.

Soil Survey Staff. 2018. U.S. Department of Agriculture-Natural Resources Conservation Service (USDA-NRCS) official soil series description view by list. (Accessed on 2 November 2018). Soilseries.sc.egov.usda.gov.

Weatherbase. 2018. Beltsville, Maryland travel weather averages. (Accessed on 2 November 2018). https://www.weatherbase.com/weather/weather.php3?s=7081.

Ye, W., X. Li, X. Chen, and G. Zhang. 2014. A spectral index for highlighting forest cover from remotely sensed imagery. In SPIE Asia Pacific Remote Sensing II 92601L92601L. https://doi.org/10.1117/12.2068775.

Yuan, F., K. E. Sawaya, B. C. Loeffelholz, and M. E. Bauer. 2005. Land cover classification and change analysis of the Twin Cities (Minnesota) Metropolitan Area by multitemporal Landsat remote sensing. Remote Sensing of Environment 98(23):317-328. https://doi.org/10.1016/j.rse.2005.08.006.

Zhang, L., X. Sun, T. Wu, and H. Zhang. 2015. An analysis of shadow effects on spectral vegetation indexes using a ground-based imaging spectrometer. In IEEE Geoscience and Remote Sensing Letters, 12(11): 2188-2192. doi: 10.1109/LGRS.2015.2450218. 


\section{Appendix A: Confusion Matrix for Landsat-7, 16 August 2012, Calculated With ENVI Classic}

Figure A1. Output matrix trial.

\begin{tabular}{|c|c|c|c|c|}
\hline \multicolumn{4}{|c|}{ output matrix trial } & \\
\hline \multicolumn{2}{|c|}{$\begin{array}{l}\text { Overall Accuracy }=(380 / 398) \\
\text { Kappa Coefficient }=0.9055\end{array}$} & $95.4774 \%$ & & \\
\hline \multicolumn{4}{|c|}{ Ground Truth (Pixels) } & \\
\hline Class & ROI:NOT TREE & ROI : TREE & Total & \\
\hline Unclassified & 0 & 0 & 0 & \\
\hline NOT TREE [Blu & 232 & 0 & 232 & \\
\hline TREE [Red] 51 & 18 & 148 & 166 & \\
\hline Total & 250 & 148 & 398 & \\
\hline \multicolumn{4}{|c|}{ Ground Truth (Percent) } & \\
\hline Class & ROI:NOT TREE & ROI : TREE & Total & \\
\hline Unclassified & 0.00 & 0.00 & 0.00 & \\
\hline NOT TREE [Blu & 92.80 & 0.00 & 58.29 & \\
\hline TREE [Red] 51 & 7.20 & 100.00 & 41.71 & \\
\hline Total & 100.00 & 100.00 & 100.00 & \\
\hline Class & $\begin{array}{r}\text { Commission } \\
\text { (Percent) }\end{array}$ & $\begin{array}{l}\text { Omission } \\
\text { (Percent) }\end{array}$ & $\begin{array}{l}\text { Commission } \\
\text { (Pixels) }\end{array}$ & $\begin{array}{l}\text { Omission } \\
\text { (Pixels) }\end{array}$ \\
\hline & 0.00 & 7.20 & $0 / 232$ & $18 / 250$ \\
\hline TREE [Red] 51 & 10.84 & 0.00 & $18 / 166$ & $0 / 148$ \\
\hline Class & $\begin{array}{l}\text { Prod. Acc. } \\
\text { (Percent) }\end{array}$ & $\begin{array}{l}\text { User Acc. } \\
\text { (Percent) }\end{array}$ & $\begin{array}{l}\text { Prod. Acc. } \\
\text { (Pixels) }\end{array}$ & $\begin{array}{l}\text { User Acc. } \\
\text { (Pixels) }\end{array}$ \\
\hline NOT TREE [Blu & 92.80 & 100.00 & $232 / 250$ & $232 / 232$ \\
\hline TREE [Red] 51 & 100.00 & 89.16 & $148 / 148$ & $148 / 166$ \\
\hline
\end{tabular}


Table A1. Confusion matrix for stratified-random accuracy approach, Landsat-7, 16 August 2012, calculated with ArcGIS using unbiased areal proportions.

\begin{tabular}{|l|l|l|l|l|l|l|l|}
\hline & & Tree & No Tree & Total & Pixels(Map) & UA & UA Cl \\
\hline & Tree & 0.6443 & 0.0576 & 0.7019 & 64247 & $91.79 \%$ & $0.28 \%$ \\
\hline & No Tree & 0.0707 & 0.2274 & 0.2981 & 27288 & $76.28 \%$ & $0.39 \%$ \\
\hline & Total & 0.7150 & 0.2850 & 1.0000 & 91535 & & \\
\hline $\begin{array}{l}\text { Unbiased } \\
\text { areal estimate }\end{array}$ & Area(ha) & $5,890.36$ & $2,347.79$ & & & & \\
\hline $\begin{array}{l}\text { Error amount } \\
\text { (ha) }\end{array}$ & S(area)ha & 134.46 & 134.46 & & & & \\
\hline $\begin{array}{l}\text { Error amount } \\
\text { (Cl) }\end{array}$ & $95 \%$ & 263.55 & 263.55 & & & & \\
\hline $\begin{array}{l}\text { Adjusted } \\
\text { producer's } \\
\text { accuracy }\end{array}$ & PA & $90.11 \%$ & $79.79 \%$ & & & & \\
\hline Cl for PA & PA Cl & $0.3 \%$ & $0.4 \%$ & & & & \\
\hline $\begin{array}{l}\text { Overall } \\
\text { Accuracy }\end{array}$ & $87.17 \%$ & & & & & & \\
\hline
\end{tabular}




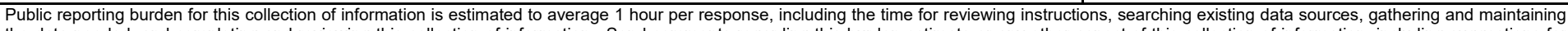

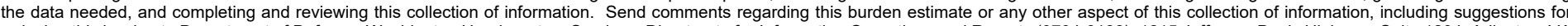

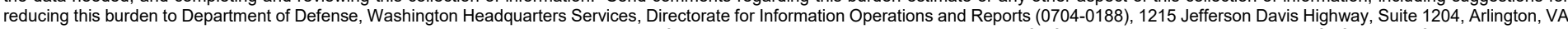

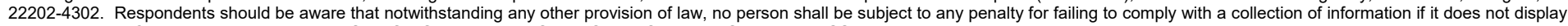
a currently valid OMB control number. PLEASE DO NOT RETURN YOUR FORM TO THE ABOVE ADDRESS.
1. REPORT DATE (DD-MM-YYYY)
2. REPORT TYPE
3. DATES COVERED (From - To)

September 2019

Final report

\section{TITLE AND SUBTITLE}

Forest Cover Index for Tree Cover Detection Using Landsat-7 Multispectral Imagery

5a. CONTRACT NUMBER

5b. GRANT NUMBER

5c. PROGRAM ELEMENT NUMBER

6. AUTHOR(S)

Luisa I. Feliciano-Cruz, Sarah J. Becker, Kristofer D. Lasko, Craig S. T. Daughtry, and Andrew L. Russ

5d. PROJECT NUMBER

405906

5e. TASK NUMBER

5f. WORK UNIT NUMBER

8. PERFORMING ORGANIZATION REPORT NUMBER

ERDC/GRL TR-19-1
U.S. Army Engineer Research and Development Center

Geospatial Research Laboratory (GRL)

7701 Telegraph Road, Alexandria, VA 22315;

Hydrology and Remote Sensing Laboratory

U.S. Department of Agriculture (USDA) Agricultural Research Service

5601 Sunnyside Avenue, Beltsville, MD 20705

9. SPONSORING / MONITORING AGENCY NAME(S) AND ADDRESS(ES)

Headquarters, U.S. Army Corps of Engineers

Washington, DC 20314-1000
10. SPONSOR/MONITOR'S ACRONYM(S)

USACE

11. SPONSOR/MONITOR'S REPORT NUMBER(S)

\section{DISTRIBUTION / AVAILABILITY STATEMENT}

Approved for public release; distribution unlimited.

\section{SUPPLEMENTARY NOTES}

\section{ABSTRACT}

Forest cover monitoring using satellite imagery is important to U.S. military terrain analysis. Mobility models, cover and concealment, and precise surface feature delineation all rely on an accurate forest/non-forest cover layer. However, the challenge remains in distinguishing trees from other vegetative land covers when relying on single date imagery. A Forest Cover Index (FCI) algorithm was previously developed on Worldview-2 imagery and was designed to separate forest cover from non-forest covered areas. In this research, the FCI algorithm was applied to Landsat-7 imagery using the analogous red (636-673 nanometers (nm)) and near-infrared bands $(851-878 \mathrm{~nm})$ from a peak summer image on 16 August 2012 . The results obtained with Landsat-7 imagery proved satisfactory with an overall accuracy (tree cover versus non-tree cover) of $>83$ percent, according to testing with two different accuracy assessment tests. The application of the FCI to Landsat-7 imagery broadens the applicability of the FCI to freely available imagery.

15. SUBJECT TERMS

\begin{tabular}{l|l|l}
\hline $\begin{array}{l}\text { a. } \text { REPORT } \\
\text { UNCLASSIFIED }\end{array}$ & $\begin{array}{l}\text { b. ABSTRACT } \\
\text { UNCLASSIFIED }\end{array}$ & $\begin{array}{c}\text { c. THIS PAGE } \\
\text { UNCLASSIFIED }\end{array}$
\end{tabular}
Trees
Forest cover indices

\section{SECURITY CLASSIFICATION OF:}

Land cover--Remote sensing

Remote-sensing images

Multispectral imaging

17. LIMITATION
OF ABSTRACT

\section{NUMBER OF PAGES}

26 19a. NAME OF RESPONSIBLE PERSON

19b. TELEPHONE NUMBER (include area code) 